\title{
The Stochastic Dominance Violation of Index Call Options in the Presence of Market Makers
}

\author{
Sang Baum Kang \\ Stuart School of Business, Illinois Institute of Technology, Chicago, USA \\ Email: skang21@stuart.iit.edu
}

How to cite this paper: Kang, S.B. (2018) The Stochastic Dominance Violation of Index Call Options in the Presence of Market Makers. Theoretical Economics Letters, 8, 1614-1622. https://doi.org/10.4236/tel.2018.89103

Received: April 26, 2018

Accepted: June 10, 2018

Published: June 13, 2018

Copyright (C) 2018 by author and Scientific Research Publishing Inc. This work is licensed under the Creative Commons Attribution International License (CC BY 4.0).

http://creativecommons.org/licenses/by/4.0/

(c) (i) Open Access

\begin{abstract}
Finance researchers have been debating over whether index options are overpriced. Most debates have focused on expensive out-of-the-money put options. However, the stochastic dominance literature has argued that S \& P 500 Index call options are frequently overpriced in the sense that every rational agent can improve her expected utility by writing these call options that violate the stochastic dominance upper bound. Hence, expensive index call options are also an unsolved puzzle in the finance literature. On the other hand, recent finance papers find that market makers play an important role in the pricing of index options. In this paper, I explore how constrained market makers interact with heterogeneity in beliefs and index option prices. Specifically, I develop an equilibrium model that accommodates previous empirical/theoretical results related to heterogeneity in beliefs, limits or arbitrage, and the role of market makers. The incremental findings from my model can be summarized as follows. First, even with the presence of market makers, the stochastic dominance upper bound violation of index call options occurs when heterogeneity in beliefs is sufficiently large. This result is novel, insomuch as someone may argue that if heterogeneous end-users share the risk themselves, heterogeneity in the presence of constrained market makers may not lead to option mispricing. Second, as the market maker is more constrained, the stochastic dominance upper bound violation becomes more severe. This paper is related to and contributes to the growing literature on the puzzle of index options. In addition, this paper complements the literature on the role of market makers in index option markets and the stochastic dominance literature.
\end{abstract}

\section{Keywords}

Heterogeneity in Beliefs, Index Option, Stochastic Dominance, Market Maker

\section{Introduction}

Finance researchers have been debating over whether index options are over- 
priced [1] [2] [3] [4]. Most debates have focused on expensive out-of-the-money (hereafter, OTM) put options [5] [6]. However, the stochastic dominance (hereafter, SD) literature has documented that index call options are also too expensive. Specifically, [7] and [8] argued that Standard and Poor's 500 (hereafter, $S \&$ P 500) Index call options are frequently overpriced in the sense that every rational agent can improve her expected utility by writing these call options that violate the SD upper bound. Hence, expensive index call options are also an unsolved puzzle in the finance literature.

SD upper bounds are the preference-free reservation write prices of call and put options, which are the minimum option price at which any rational agent is willing to write an option to increase her expected utility [9] [10] [11] [12]. SD upper bounds are often deemed the maximum possible option price in the absence of mispricing between an underlying security and the corresponding option. However, [7] and [8] found that SD upper bounds are frequently violated in the S \& P 500 call option market. The conventional explanation for expensive options, in which the demand is driven by OTM put options for insurance purposes against steep market declines (e.g., [13] and [14]), is inconsistent with massive overpricing of index call options.

Kang [15] proposed an economic model examining heterogeneity in investors' prior beliefs as a potential explanation for expensive call option prices and their stochastic dominance violation. In Kang's [15] economic setting, bullish and bearish agents, who participate in both stock and option markets, have different beliefs on the expected return on the stock. He finds that if these agents are sufficiently heterogeneous, the bullish agent, who seeks "exposure" to a stock, purchases an overpriced call option from the constrained bearish agent. For simplicity, he abstracts out the presence of market makers. However, recent finance papers ([16] [17], among many others) find that market makers play an important role in the pricing of index options.

In this paper, I explore how constrained market makers interact with heterogeneity in beliefs and index options prices. Specifically, I develop an equilibrium model that accommodates several empirical/theoretical results documented in the finance literature:

1) Heterogeneity in Beliefs: The optimal holding of options increases as heterogeneity in beliefs increases [18]. In the presence of heterogeneity in beliefs and portfolio constraints, option mispricing is required for the market to clear [19].

2) Limits of Arbitrage: Because of limits-of-arbitrage (e.g., market friction and finite wealth), market participants cannot completely eliminate the "good-sell opportunities" of options [20] [21] [22].

3) The Role of Market Makers: The end-user demand for index options is positive, and market makers provide liquidity [16] [23]. Market makers' capability to supply option liquidity is limited, and such a limitation may be a determinant for option pricing (for a related discussion, see, e.g. [16] [17] [21] 
[22] and [24]). As the net end-user demand increases, the option price increases because market makers with limited risk-sharing capability demand higher option premia at equilibrium [16].

My model illustrates why heterogeneity increases the net end-user demand (and the equilibrium price of a call option), and how the market maker's limited capability is related to the SD upper bound violation. I keep my stylized heterogeneous-agent model as simple as possible; my model has the bare minimum ingredients to endogenize the aforementioned prior findings in the finance literature. The incremental findings from my model can be summarized as follows. First, even with the presence of market makers, the SD upper bound violation of index call options occurs when heterogeneity in beliefs is sufficiently large. This result is novel, insomuch as someone may argue that if heterogeneous end-users share the risk themselves, heterogeneity in the presence of constrained market makers may not lead to option mispricing. Second, as the market maker is more constrained, the SD upper bound violation becomes more severe.

This paper is related to and contributes to the growing literature on the puzzle of index options. In addition, this paper complements the literature on the role of market makers in index option markets (e.g., [16] [17] [21] and [24]) and the SD literature [7]-[12].

The remainder of this paper is structured as follows. Section 2 briefly discusses related literature. Section 3 proposes my model. Section 4 reports the numerical results and summarizes my findings. Section 5 concludes.

\section{Related Literature}

[1] and [2] reported that S \& P 500 Index option prices (returns) are too high (low) relative to classical asset pricing models and may reflect a negative premium for additional factors, such as volatility risk. [5] argued that the S \& P 500 Index put options are massively overpriced because the high option prices in their post-1987 crisis sample are inconsistent with a wide range of asset pricing models. Using Broadie et al.'s ([3]) method, [6] documented that put options were overpriced from 1987 to 2012. ${ }^{1}$ Furthermore, [4] argued that the excess returns of the European index option portfolio are attributed, not to jump or variance risk premia, but to option mispricing. The literature has proposed several explanations to the question: If options are too expensive, why is this? The explanations range from state-dependent dead-weight costs to non-hedgeable risk, volatility and jump risk premia, end-user demand, liquidity risk, the Peso problem, biased beliefs, and so forth (see, e.g., [5] [16] [25] [26] [27] [28] and [29]). However, heterogeneity has received insufficient attention, and research in heterogeneity vs. expensive index options is thin. The current paper fills this gap in the literature.

${ }^{1}$ Broadie et al. [3] did not find statistical evidence from their parametric Monte-Carlo test that individual put options are more expensive than their benchmark models, such as the Black-Scholes-Merton model. They argued that the high returns of option strategies may be explained by jump risk premia and sampling error. However, replicating their work for a longer sample of 1987 to 2002, Chambers et al. [6] find that put options are mispriced. 


\section{The Model}

In this section, I propose a heterogeneous-agent model adapted from [15] where rational agents equipped with heterogeneous beliefs trade a stock and its option. My stylized economy has two risk-averse end-users of index call options. These two end-users are heterogeneous in their beliefs in the expected output. One end-user expects high output, and the other expects low output. Because of the well-known leverage effect, the bearish end-user expects high uncertainty, while the bullish end-user expects low uncertainty. They trade a claim on an output (i.e., stock) and a call option on the stock in order to maximize their expected utilities under their subjective beliefs. In addition to the end-users, I have in my stylized economy a market maker who supplies the call option to meet the end-users' net demand for the call option. The market maker's role is to provide liquidity, but its capability of writing the call option is limited.

A simple one-period economy has a single consumption good and one underlying risky asset. One underlying asset (stock) at the beginning of the period returns $\tilde{S}$ number of consumption goods at the end of the period. In this stylized economy, the bullish end-user (agent $A$, hereafter) and the bearish end-user (agent $B$, hereafter) are endowed with 1 stock each, and they trade their shares of the underlying asset and the call option at the beginning of the period. The call option with the strike $K$ pays

$$
\tilde{c} \equiv \max [\tilde{S}-K, 0]
$$

at the end of the period. Because this call option is a derivative security, its net supply is zero. Agent $i$ believes

$$
\tilde{S}=\hat{S}_{i}+\hat{\sigma}_{i} Z
$$

where $i=A$ or $B ; \hat{S}_{i}$ is agent $i$ 's belief on the expected output; $\hat{\sigma}_{i}$ is agent $i$ 's belief on the standard deviation of the output; and $Z$ is a standard normal random variable. Agent $i$ is risk-averse with the utility function $u\left(W_{i}\right)=-\exp \left(-\gamma W_{i}\right)$, where $W_{i}$ is agent $i$ 's end-of-the-period wealth. The agents trade the stock and the option in order to maximize their $E\left[u\left(W_{i}\right)\right] \mathrm{s}$.

The agents in my economy are heterogeneous in their beliefs on $\hat{S}_{i}$ and $\hat{\sigma}_{i}$. The bullish end-user $A$ expects a higher $\hat{S}_{i}$ than the bearish end-user $B ; \mathrm{I}$ set $\hat{S}_{A}=(1+H) \hat{S}_{a v g}$ and $\hat{S}_{B}=(1-H) \hat{S}_{\text {avg }}$, where $\hat{S}_{a v g}$ is the average of the two end-users' beliefs on $\hat{S}_{i}$ and $H \geq 0$ is a parameter for heterogeneity in beliefs (hereafter, HIB). Because of the well-known leverage effect, the bearish end-user $B$ expects higher uncertainty than the bullish end-user $A$; I set $\hat{\sigma}_{A}=(1-H \cdot L) \hat{\sigma}_{\text {avg }}$ and $\hat{\sigma}_{B}=(1+H \cdot L) \hat{\sigma}_{\text {avg }}$, where $\hat{\sigma}_{\text {avg }}$ is the average of the two end-users' beliefs on $\hat{\sigma}_{i}$, and $L \geq 0$ is a parameter for the leverage effect. As in other papers studying heterogeneity in beliefs and mispricing (e.g., [19], among many others), I impose stock short-sell limits on these end-users. ${ }^{2}$ However, I do not impose any position limits on call options, because in the real ${ }^{2}$ Even when some amount of stock short-selling is allowed, the main results qualitatively stay the same. 
world, taking a long or short position in derivative security is easier than short-selling the stock. I consider another agent, the market maker who supplies the net demand of the call options by the end-users. Because market makers' limited supply of options may create limits of arbitrage ([17] [20] [21] and [22]), I impose a call supply limit of the market maker. The end-users and market maker in the economy maximize their expected utility by optimally determining their stock and option positions similarly to [15].

\section{Numerical Results}

I numerically compute the equilibrium prices and trading volumes of the securities in the aforementioned economy. In this section, we consider an out-of-the-money call option $\left(\hat{S}_{\text {avg }}=10\right.$ and $\left.\mathrm{K}=11\right)$ and assume reasonable volatility $\left(\hat{\sigma}_{a v g}=0.10\right)$ and leverage factor $(L=1.6)$. Figure 1 summarizes the equilibria of my economy for varying degrees of HIB. The middle panel reports the two end-users' supply and demand by HIB. When HIB is zero (i.e., no heterogeneity in beliefs), both the bullish end-user's demand (thick solid line) and the bearish end-user's supply (thin dashed line) are zero, because both end-users' subjective valuations of the call option are identical, and no option trading occurs. When HIB is greater than zero, the bullish end-user demands the call option, and the bearish end-user supplies the call option because the bullish end-user's subjective valuation of the call option is greater than the bearish end-user's one. As HIB increases, both the bullish end-user's demand and the bearish end-user's supply increase, as the middle panel depicts. However, because the bearish end-user expects higher volatility than the bullish end-user, the bearish end-user's bearish view on the call option is less extreme than the bullish end-user's bullish view on the call option. Hence, the bearish end-user's supply of the call option increases more slowly (as HIB increases), than the bullish end-user's demand for the call option. It follows that the net demand for the call option, defined as the difference between the bullish end-user's demand and the bearish end-user's supply, is positive and increases as HIB increases.

Observe from the left panel that as HIB increases, the net demand becomes more positive, and the market marker's supply becomes more negative; these two sides are precisely offset, because otherwise, the market does not clear. Observe that the net demand is capped by +1 , because the market maker's capability to supply the call option is limited $(-1)$. The equilibrium call option price is determined such that the net demand is equal to the supply by the market maker with limited risk-sharing capability. In the right panel, I compare the equilibrium call price with the SD upper bounds, as in [15]. Observe that the call option's SD upper bound is violated for a sufficiently large HIB.

Figure 2 summarizes the equilibrium prices and volumes for varying sizes of the call supply limit of the market maker. From the left panel, observe that when the call supply constraint is sufficiently loose (greater than -2.2 in an absolute value), the market maker's call supply limit is not binding. Only when the call 

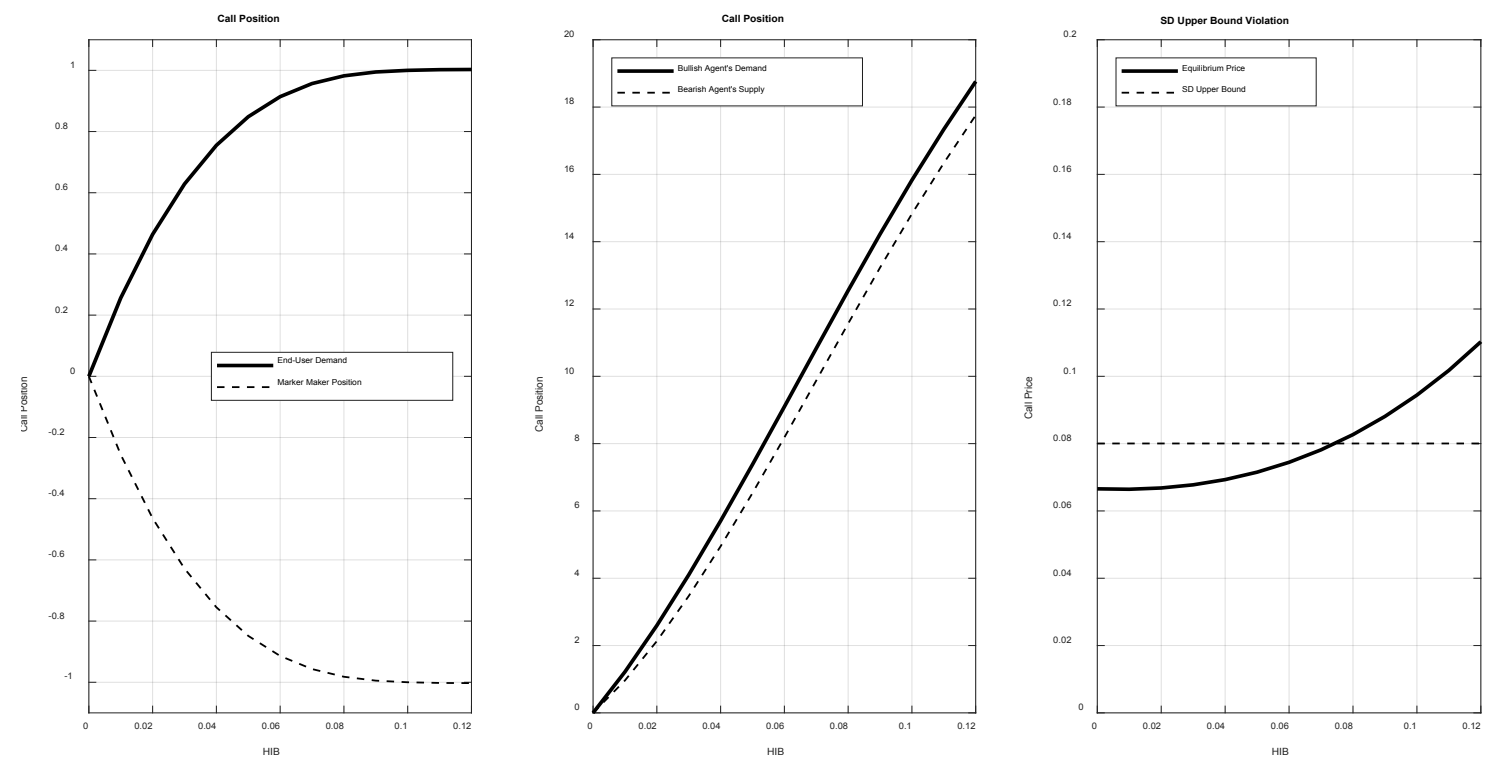

Figure 1. The left figure depicts the net end-user demand (thick solid line), defined as the bullish end-user's demand minus the bearish end-user's supply, as well as the market maker's position (thin dashed line) in our stylized economy. Specifically, we use $\mathrm{L}=1.6 . \hat{\mathrm{S}}_{\mathrm{avg}}=10 ; \hat{\sigma}_{\mathrm{avg}}=1.0 ; \mathrm{K}=11 ; \mathrm{T}=1 ; \mathrm{r}=0.03$; and the call supply limit of the market maker $=-1$. We vary $\mathrm{H}$ from 0 to 0.12 to calculate the equilibrium prices and volumes for different degrees of HIB. The middle figure shows the demand for the call by the bullish end-user (thick solid line) and the supply of the call by the bearish end-user (thin dashed line). Finally, the right figure depicts the equilibrium call price in our stylized economy (thick solid line) and the SD upper bound (thin dashed line).
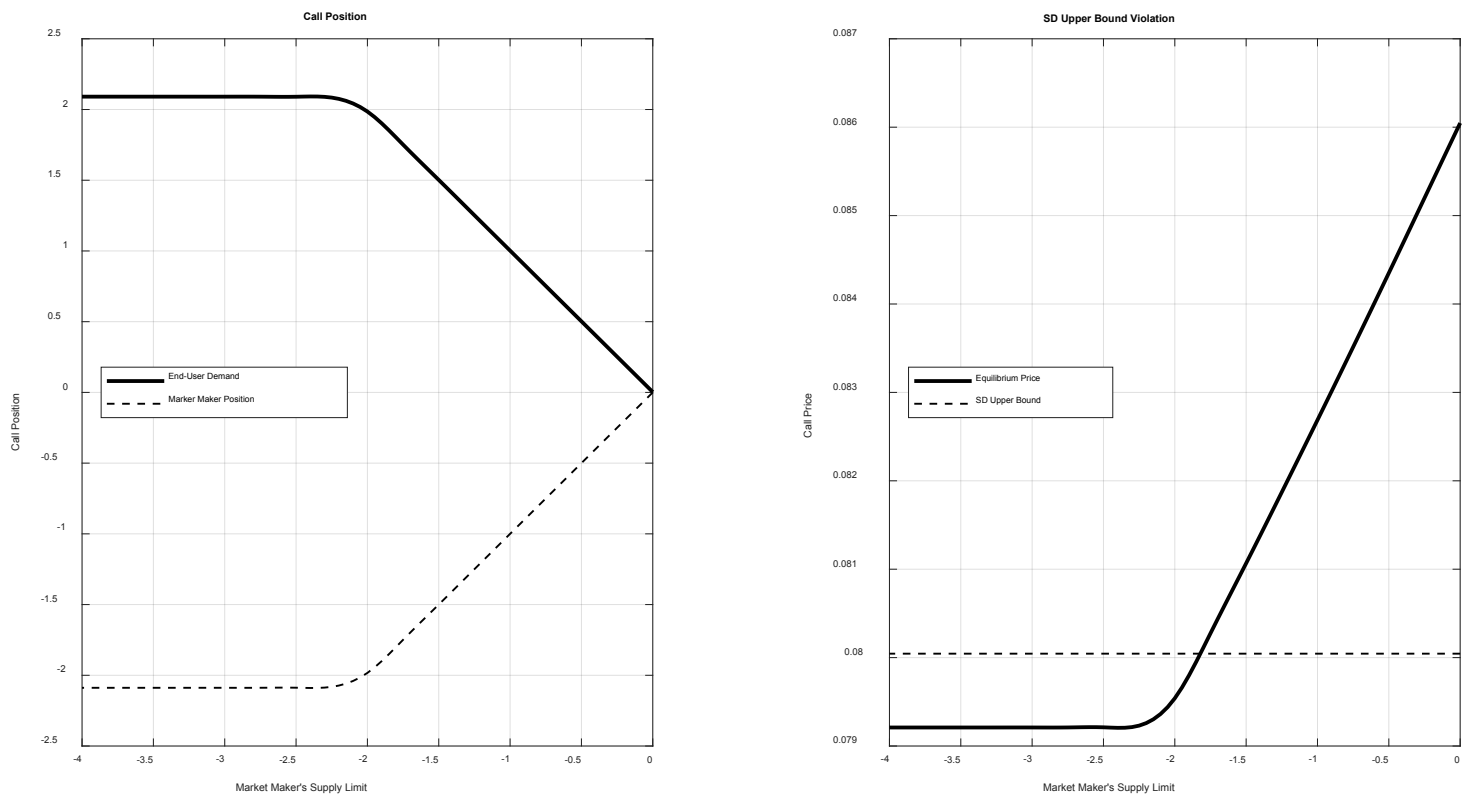

Figure 2. The left figure depicts the net end-user demand (thick solid line), defined as the bullish end-user's demand minus the bearish end-user's supply, as well as the market maker's position (thin dashed line) in our stylized economy. Specifically, we use $\mathrm{L}=1.6 . \hat{\mathrm{S}}_{\mathrm{avg}}=10 ; \hat{\sigma}_{\text {avg }}=1.0 ; \mathrm{K}=11 ; \mathrm{T}=1 ; \mathrm{r}=0.03$; and $\mathrm{H}=0.08$. We vary the call supply limit of the market maker from -4 to 0 to calculate the equilibrium prices and volumes for different sizes of the call supply limit of the market maker. The right figure depicts the equilibrium call price in our stylized economy (thick solid line) and the SD upper bound (thin dashed line). 
supply constraint of the market maker is sufficiently tight (less than -2.2 in an absolute value) is the call supply limit binding, and the equilibrium call price increases as the market maker is more constrained. The right panel shows that when the call supply constraint is sufficiently loose, the equilibrium call price does not increase as the market maker is more constrained. Only when the call supply constraint of the market maker is sufficiently tight does the equilibrium call price increase as the market maker's call supply is more constrained. When the market maker is sufficiently constrained, the call price violates the SD upper bound. ${ }^{3}$

The findings from my stylized model can be summarized as follows. In equilibrium, the bullish end-user demands the call option, and the bearish end-user supplies the call option. Because the bearish end-user expects higher volatility than the bullish end-user, the bearish end-user's bearish view on the call option is less severe than the bullish end-user's bullish view on the call option. Hence, the bearish end-user's supply of the call option is less than the bullish end-user's demand for the call option. Thus, the net demand for the call option is positive. Furthermore, the net demand (i.e., the difference between the bullish end-user's demand and the bearish end-user's supply) increases as HIB increases. Because of the market clearing condition, the net demand of the end-users is constrained by the market maker's call supply limit. As HIB increases, the market maker asks for a higher call option premium for the market to clear. For a sufficiently large HIB, the market price of the call option violates the SD upper bound. ${ }^{4}$ Furthermore, as the market maker is more financially constrained, the degree of the SD upper bound violation increases.

\section{Conclusions}

From my model, one can derive two testable hypotheses:

1) HIB increases the $S D$ upper bound violation and

2) The increase of the $S D$ upper bound violation in HIB is more pronounced when the market marker's wealth/funding liquidity is low.

The current research opens a new avenue for future research. First, an empiricist may contribute to the literature by testing the aforementioned two hypotheses. Second, the analysis in this paper may be extended to individual stock options. According to [30], trading activity by non-market-maker investors of call options on an individual stock is four times as large as that of put options. A researcher may investigate whether the heterogeneity in the beliefs of investors may provide any insights into the pricing of individual options.

The results documented in this paper may be relevant to practitioners, as well. Traders, risk managers, and regulatory bodies may want to trace measures for the HIB in order to monitor how expensive index call options can be.

${ }^{3}$ The reader should exercise caution when interpreting the size of the quantitative results because the stylized nature of the model makes only qualitative directions meaningful.

${ }^{4}$ This paper focuses on the expensive index call options, but according to the put-call parity, the index put option prices also increase as HIB increases. 


\section{References}

[1] Coval, J.D. and Shumway, T. (2001) Expected Option Returns. Journal of Finance, 56, 983-1009. https://doi.org/10.1111/0022-1082.00352

[2] Bakshi, G. and Kapadia, N. (2003) Delta-Hedged Gains and the Negative Market Volatility Risk Premium. Review of Financial Studies, 16, 527-566.

https://doi.org/10.1093/rfs/hhg002

[3] Broadie, M., Chernov, M. and Johannes, M. (2009) Understanding Index Option Returns. Review of Financial Studies, 22, 4493-4529. https://doi.org/10.1093/rfs/hhp032

[4] Faias, J.A. and Santa-Clara, P. (2017) Optimal Option Portfolio Strategies: Deepening the Puzzle of Index Option Mispricing. Journal of Financial and Quantitative Analysis, 52, 277-303. https://doi.org/10.1017/S0022109016000831

[5] Bondarenko, O. (2014) Why Are Put Options So Expensive? Quarterly Journal of Finance, 4, No. 3. https://doi.org/10.1142/S2010139214500153

[6] Chambers, D.R., Foy, M., Liebner, J. and Lu, Q. (2014) Index Option Returns: Still Puzzling. Review of Financial Studies, 27, 1915-1928.

https://doi.org/10.1093/rfs/hhu020

[7] Constantinides, G.M., Jackwerth, J.C. and Perrakis, S. (2009) Mispricing of S \& P 500 Index options. Review of Financial Studies, 22, 1247-1277. https://doi.org/10.1093/rfs/hhn009

[8] Constantinides, G.M., Czerwonko, M., Jackwerth, J.C. and Perrakis, S. (2011) Are Options on Index Futures Profitable for Risk Averse Investors? Empirical Evidence. Journal of Finance, 66, 1407-1437. https://doi.org/10.1111/j.1540-6261.2011.01665.x

[9] Ritchken, P.H. (1985) On Option Pricing Bounds. Journal of Finance, 40, 1219-1233. https://doi.org/10.1111/j.1540-6261.1985.tb02373.x

[10] Levy, H. (1992) Stochastic Dominance and Expected Utility: Survey and Analysis. Management Science, 38, 555-593. https://doi.org/10.1287/mnsc.38.4.555

[11] Constantinides, G.M. and Perrakis, S. (2002) Stochastic Dominance Bounds on Derivatives Prices in a Multiperiod Economy with Proportional Transaction Costs. Journal of Economic Dynamics and Control, 26, 1323-1352. https://doi.org/10.1016/S0165-1889(01)00047-1

[12] Constantinides, G.M. and Perrakis, S. (2007) Stochastic Dominance Bounds on American Option Prices in Markets with Frictions. Review of Finance, 11, 71-115. https://doi.org/10.1093/rof/rfl001

[13] Buraschi, A., Trojani, F. and Vedolin, A. (2014) When Uncertainty Blows in the Orchard: Comovement and Equilibrium Volatility Risk Premia. Journal of Finance, 69, 101-137. https://doi.org/10.1111/jofi.12095

[14] Bates, D.S. (2000) Post-'87 Crash Fears in the S \& P 500 Futures Option Market. Journal of Econometrics, 94, 181-238. https://doi.org/10.1016/S0304-4076(99)00021-4

[15] Kang, S.B. (2017) A Simple Model to Explain Expensive Index Call Options. Theoretical Economics Letters, 7, 316-323. https://doi.org/10.4236/tel.2017.73024

[16] Garleanu, N., Pedersen, L.H. and Poteshman, A.M. (2009) Demand-Based Option Pricing. Review of Financial Studies, 22, 4259-4299. https://doi.org/10.1093/rfs/hhp005

[17] Fournier, M. and Jacobs, K. (2016) Inventory Risk, Market-Maker Wealth, and the Variance Risk Premium: Theory and Evidence. Rotman School of Management 
Working Paper (2334842), Toronto.

[18] Buraschi, A. and Jiltsov, A. (2006) Model Uncertainty and Option Markets with Heterogeneous Beliefs. Journal of Finance, 61, 2841-2897. https://doi.org/10.1111/j.1540-6261.2006.01006.x

[19] Basak, S. and Croitoru, B. (2000) Equilibrium Mispricing in a Capital Market with Portfolio Constraints. Review of Financial Studies, 13, 715-748. https://doi.org/10.1093/rfs/13.3.715

[20] Bates, D. (2003) Empirical Option Pricing: A Retrospection. Journal of Econometrics, 116, 387-404. https://doi.org/10.1016/S0304-4076(03)00113-1

[21] Santa-Clara, P. and Saretto, A. (2009) Option Strategies: Good Deals and Margin Calls. Journal of Financial Markets, 12, 391-417. https://doi.org/10.1016/j.finmar.2009.01.002

[22] Gromb, D. and Vayanos, D. (2010) Limits of Arbitrage: The State of the Theory. Annual Review of Financial Economics, 2, 251-275. https://doi.org/10.1146/annurev-financial-073009-104107

[23] Bollen, N.P. and Whaley, R.E. (2004) Does Net Buying Pressure Affect the Shape of Implied Volatility Functions? Journal of Finance, 59, 711-753.

[24] Leippold, M. and Su, L. (2015) Collateral Smile. Journal of Banking \& Finance, 58, 15-28. https://doi.org/10.1016/j.jbankfin.2015.03.019

[25] Brown, G.W. and Toft, K.B. (2002) How Firms Should Hedge. Review of Financial Studies, 15, 1283-1324. https://doi.org/10.1093/rfs/15.4.1283

[26] Carr, P. and Wu, L. (2009) Variance Risk Premiums. Review of Financial Studies, 22, 1311-1341. https://doi.org/10.1093/rfs/hhn038

[27] Christoffersen, P.F., Heston, S. and Jacobs, K. (2013) Capturing Option Anomalies with a Variance-Dependent Pricing Kernel. Review of Financial Studies, 26, 1962-2006. https://doi.org/10.1093/rfs/hht033

[28] Todorov, V. (2010) Variance Risk-Premium Dynamics: The Role of Jumps. Review of Financial Studies, 23, 345-383. https://doi.org/10.1093/rfs/hhp035

[29] Bongaerts, D., De Jong, F. and Driessen, J. (2011) Derivative Pricing with Liquidity Risk: Theory and Evidence from the Credit Default Swap Market. Journal of Finance, 66, 203-240. https://doi.org/10.1111/j.1540-6261.2010.01630.x

[30] Lakonishok, J., Lee, I., Pearson, N.D. and Poteshman, A.M. (2007) Option Market Activity. Review of Financial Studies, 20, 813-857.

https://doi.org/10.1093/rfs/hhl025 